Asian J. Med. Biol. Res. 2019, 5 (4), 292-296; doi: 10.3329/ajmbr.v5i4.45267

\author{
Asian Journal of \\ Medical and Biological Research \\ ISSN 2411-4472 (Print) 2412-5571 (Online) \\ www.ebupress.com/journal/ajmbr
}

Article

\title{
A survey-based study on awareness of eye diseases among population of Bangladesh
}

Nishat Nasrin ${ }^{1}$, Muhammad Asaduzzaman ${ }^{2 *}$, Dilruba Sharmin ${ }^{2}$, Nigar Sultana Tithi ${ }^{1}$ and Syed Md. Nazmul Hudda $^{1}$

${ }^{1}$ Department of Pharmacy, East West University, Jahurul Islam City Gate, A/2 Jahurul Islam Ave, Dhaka-1212

Bangladesh

${ }^{2}$ Department of Clinical Pharmacy and Pharmacology, University of Dhaka, Dhaka-1000, Bangladesh

*Corresponding author: Muhammad Asaduzzaman, Department of Clinical Pharmacy and Pharmacology, University of Dhaka, Dhaka-1000, Bangladesh. E-mail: asaduzzaman@du.ac.bd

Received: 09 October 2019/Accepted: 27 November 2019/ Published: 31 December 2019

\begin{abstract}
Awareness of common eye diseases and their early detection can play a vital role in encouraging people to seek timely eye care and therefore help in reducing the burden of visual impairment. This study was designed to reveal the assessment of awareness of eye diseases among the population of Bangladesh in different locations. For this, a total of 750 respondents were selected by convenient sampling and were interviewed using a structured questionnaire. From this study, we found that only $50 \%$ of the respondents were aware of glaucoma and only $35 \%$ had knowledge about glaucoma. About $52 \%$ of the study population was aware of cataract and $19 \%$ of them had knowledge that the risk of cataract increases by getting older. About $38 \%$ of the participants had an understanding of night blindness. Diabetes can lead to eye diseases and this was known to $40 \%$ of the study population. Only $23 \%$ of the respondents were concern about their family's present eye health condition. Frequency of taking nutritional food for optimum health was very poor. Daily nutritional foods were taken by $17 \%$ of the participants. About $36 \%$ of study subjects maintained their blood pressure and obesity. From our survey results, it can be implied that the level of awareness and knowledge about common eye diseases among the population of Bangladesh was not satisfactory. Highlighting importance to the tertiary eye care, imposing health education and raising awareness will assist to understand the importance of routine eye examination for early detection and treatment of such conditions.
\end{abstract}

Keywords: eye diseases; awareness; risk factors; health education; Bangladesh

\footnotetext{
1. Introduction

Eye diseases, a global burden, have become common for both developing and underdeveloped countries. According to WHO, worldwide 285 million people are suffering from visual impairment where 246 million have low vision (moderate or severe visual impairment) and 39 million are blind (Morone et al., 2013). The common eye diseases include refractive errors, cataract, macular degeneration, glaucoma, trachoma, and vitamin A deficiency (Ono et al., 2010). South Asia possesses three times higher prevalence of blindness and moderate or severe visual impairment than in Central Asia and globally (Jonas et al., 2014). According to the National Blindness and Low Vision Survey of Bangladesh, about $1.53 \%$ of adults (having age at least 30 years) are blind and $21.6 \%$ have low vision (having visual acuity of less than 6/12 in either one or both eyes) (Dineen et al., 2003). Major contributors for visual impairment in Bangladesh account for cataract (73.4\%) and refractive errors (18.9\%) (Dineen et al., 2003). Identification of risk factors can help to reduce the burden of these diseases. However, public awareness is also needed as poorer outcomes are generated due to lack of awareness of eye conditions (Attebo et al., 1997; Varma et al., 2011; Huang et al., 2009; Dandona et al., 2001; Shrestha et al., 2014) including prevention (Varma et al., 2011; Huang et al., 2009), eye care use (Huang et al.,
} 
2009; Müller et al., 2006; Bylsma et al., 2004), and treatment (Varma et al., 2011; Huang et al., 2009; Bylsma et al., 2004). In our study, we aimed to assess the awareness of eye diseases among the population of Bangladesh.

\section{Materials and Methods}

To assess the level of awareness among the population we designed a questionnaire to collect data from 750 people aged between 20 to 60 years old from different locations in Bangladesh. The structured questionnaire used in the study was pretested before collecting actual data on a small segment of the population. This was a prospective study and data was collected between the periods of September 2014 to February 2015. Before collecting data, verbal consent was taken from each of the respondents. There were different questions in questionnaire ranging from eye diseases to eye protection. Having heard of the eye diseases were marked as "awareness" and having an understanding of the eye diseases were marked as "knowledge" in the questionnaire. Next, the collected pieces of information were compiled and fed in Microsoft Excel and the data were analyzed for the frequency distribution of the factors addressed in the questionnaire.

\section{Results and Discussion}

In our survey, we included 750 people with $63 \%$ male and $37 \%$ female from urban and rural backgrounds with different socio-economic status (Table 1). Most of the study population was aware of glaucoma (50\%) and cataract (52\%). Night blindness was not known to $62 \%$ of the study population (Table 2). We also found only $23 \%$ of families were concern about their present eye condition. About $57 \%$ of the study population had never performed eye checkup (Table 3).

Among the study population, awareness of glaucoma and cataract was poor. In case of glaucoma, early detection and prevention can be helpful to hinder the disease progression but detection of glaucoma in an initial stage is difficult unless the patient undergoes an eye examination (Dandona et al., 2001). Hence, it is necessary to increase the level of awareness of glaucoma in our population. Most of the population of this survey knew that the risk of cataract increases by getting older. Ironically, most of them don't know the proper way of maintaining optimum eye health.

According to our study, 50\% of the study population was aware of glaucoma and 35\% had proper knowledge of the disease. A large number (65\%) of the study population had not enough knowledge of glaucoma. Knowledge of cataract (19\%) was comparatively lower than glaucoma among the study population. The knowledge about eye disease like cataract and glaucoma, depends on factors like socio-economy, educational levels, etc. which was not addressed in our study. Night blindness is a very well-known disease of the eye and usually, even rural people are aware of the disease specially for knowledge dissemination and education through public media, government and NGOs. Interestingly, knowledge of night blindness (38\%) in the present study was also poor among respondents and the underlying reasons may be multifactorial that was not explored in the study. One of the common reasons for night blindness is vitamin A deficiency. According to Rahmathullah et al., 1990, awareness and knowledge of night blindness during childhood is crucial as vitamin A deficiency is also associated with child mortality. Whether the respondents had knowledge regarding the association between inadequate vitamin A levels and night blindness was not assessed in the current study.

Blindness may occur due to diabetic retinopathy among adults 20-74 years in developed countries. Diabetic patients more frequently suffer from glaucoma, cataracts, and other disorders of the eye (Solomon et al., 2017). In our study, $17 \%$ of the population had diabetes. However, knowledge about the interaction between diabetes and eye disease was not encouraging. About $60 \%$ of the population was not concern about it.

A large gap exists between the public's knowledge and understanding of eye disease which is necessary to be recognized to promote eye health activities (Livingston et al., 1998). We found a large proportion of the study population (77\%) were not concern about their family's present eye health condition. Majority of them (57\%) had never gone for any eye test in their lifetime. The frequency of taking regular nutritional food was $17 \%$ and about $32 \%$ were not concerned about it for their optimum eye health.

Hypertension is considered to be a risk factor for several eye diseases like cataract (Yu et al., 2014), age-related macular degeneration, diabetic retinopathy (Marin Garcia and Marin-Castaño, 2014). The knowledge of maintaining blood pressure and obesity was not satisfactory. About $36 \%$ of the study subjects were aware to maintain blood pressure and obesity. Proper knowledge and education are necessary to develop awareness among the population about eye diseases. We found, about $36 \%$ of the study population was illiterate. So, along with health literacy basic or primary level of education is also needed to make eye education programs successful. 
Asian J. Med. Biol. Res. 2019, 5 (4)

Table 1. Socio-demographic characteristics of the study population.

\begin{tabular}{ll}
\hline Variables & \% of the respondents \\
\hline Gender & 63 \\
Male & 37 \\
Female & \\
Age & 83 \\
20-40 & 16 \\
$41-60$ & \\
Educational level & 36 \\
Illiterate & 45 \\
$\leq$ Higher secondary & 16 \\
Graduate & 3 \\
Postgraduate & 12 \\
Occupational level & 13 \\
Student & 17 \\
Business & 16 \\
Service holder & 25 \\
Housewife & \\
Stress on work & 65 \\
Physical & 12 \\
Mental & \\
Social & \\
\hline & \\
&
\end{tabular}

Table 2. Knowledge and awareness of the study population about associated disorders causing eye diseases.

\begin{tabular}{lll}
\hline Variables & Response & \% of the respondents \\
\hline Diabetes & Yes & 17 \\
& No & 83 \\
\hline Awareness of glaucoma & Yes & 50 \\
& No & 50 \\
\hline Knowledge of glaucoma & Yes & 35 \\
& No & 65 \\
\hline Awareness of cataract & Yes & 52 \\
& No & 48 \\
\hline Knowledge of cataract & Yes & 19 \\
& No & 81 \\
\hline Night blindness & Yes & 38 \\
& No & 62 \\
\hline Knowledge about interaction between diabetes and eye disease & Yes & 40 \\
& No & 60 \\
\hline
\end{tabular}


Asian J. Med. Biol. Res. 2019, 5 (4)

Table 3. Perception of the study population about eye care and protection.

\begin{tabular}{|c|c|c|}
\hline Variables & Response & $\%$ of the respondents \\
\hline \multirow[t]{3}{*}{ Eye checkup } & Yes & 3 \\
\hline & No & 40 \\
\hline & Never & 57 \\
\hline \multirow[t]{4}{*}{ Sleep duration } & Less than $8 \mathrm{hr}$ & 71 \\
\hline & More than $8 \mathrm{hr}$ & 17 \\
\hline & Irregular & 11 \\
\hline & Insomnia & 1 \\
\hline \multirow[t]{2}{*}{ Concern about family's present eye health condition } & Yes & 23 \\
\hline & No & 77 \\
\hline \multirow[t]{4}{*}{ Knowledge about proper frequency of sight test } & Every one year & 1 \\
\hline & Every two year & 11 \\
\hline & Every three year & 12 \\
\hline & Only if I notice a change in my eyes & 76 \\
\hline \multirow[t]{4}{*}{ Time duration in front of TV/computer/mobile } & $1-2 \mathrm{hr}$ & 29 \\
\hline & $2-4 \mathrm{hr}$ & 22 \\
\hline & More than $4 \mathrm{hr}$ & 10 \\
\hline & Irregular & 39 \\
\hline \multirow[t]{2}{*}{ Wearing sunglass for the protection of eye } & Yes & 32 \\
\hline & No & 68 \\
\hline \multirow{4}{*}{$\begin{array}{l}\text { Frequency of taking nutritional food for optimum eye } \\
\text { health }\end{array}$} & Daily & 17 \\
\hline & Twice in a week & 30 \\
\hline & Once in a week & 21 \\
\hline & Sometimes & 32 \\
\hline \multirow[t]{2}{*}{ Maintaining blood pressure and obesity } & Yes & 36 \\
\hline & No & 64 \\
\hline \multirow[t]{4}{*}{ Way of maintaining blood pressure and obesity } & Exercise & 39 \\
\hline & Diet control & 37 \\
\hline & Proper nutrition & 19 \\
\hline & Avoiding tension & 5 \\
\hline
\end{tabular}

\section{Conclusions}

Based on our survey result, it can be implied that the level of awareness and knowledge about common eye diseases among the population of Bangladesh is very much insufficient to tackle these diseases. It has become mandatory to enforce health education to mass people. Community programs can be helpful to raise awareness about the importance of early eye care to prevent long term consequences. Highlighting importance to the tertiary eye care, imposing health education and raising awareness will assist to understand the importance of routine eye examination for early detection and treatment of such conditions. In our study, we could not find the correlation between knowledge and awareness of eye disease with anticipated risk factors such as socioeconomic and educational status of the patients, age and sex due to small number of data. However, the findings of the study demands expansion of the study incorporating large number of participants for making generalization and nation-wide study about the knowledge and awareness about eye diseases among Bangladeshi population.

\section{Conflict of interest}

None to declare.

\section{References}

Attebo K, P Mitchell, R Cumming and W Smith, 1997. Knowledge and beliefs about common eye diseases. Aust N Z J Ophthalmol., 25: 283-287.

Bylsma GW, A Le, BN Mukesh, HR Taylor and CA McCarty, 2004. Utilization of eye care services by Victorians likely to benefit from eye care. Clin. Experiment. Ophthalmol., 32: 573-577.

Dandona R, L Dandona, RK John, CA McCarty and GN Rao, 2001. Awareness of eye diseases in an urban population in southern India. Bull. World Health Organ., 79: 96-102.

Dineen BP, RR Bourne, SM Ali, DM Huq and GJ Johnson, 2003. Prevalence and causes of blindness and visual impairment in Bangladeshi adults: results of the National Blindness and Low Vision Survey of Bangladesh. Br. J. Ophthalmol., 87: 820-828. 
Huang OS, WT Tay, ES Tai, JJ Wang, SM Saw, VS Jeganathan, M Sandar and TY Wong, 2009. Lack of awareness amongst community patients with diabetes and diabetic retinopathy: the Singapore Malay eye study. Ann. Acad. Med. Singap., 38: 1048-1055.

Jonas JB, R George, R Asokan, SR Flaxman, J Keeffe, J Leasher, K Naidoo, K Pesudovs, H Price, L Vijaya, RA White, TY Wong, S Resnikoff, HR Taylor and RR Bourne, 2014. Prevalence and causes of vision loss in Central and South Asia: 1990-2010. Br. J. Ophthalmol., 98: 592-598.

Livingston PM, CA McCarty and HR Taylor, 1998. Knowledge, attitudes, and self care practices associated with age related eye disease in Australia. Br. J. Ophthalmol., 82: 780-785.

Marin Garcia PJ and ME Marin-Castaño, 2014. Angiotensin II-related hypertension and eyediseases. World J. Cardiol., 6: 968-984.

Morone P, E Camacho Cuena, I Kocur and N Banatvala, 2013. Investing in eye health: securing the support of decision-makers. J. Public Health Policy, 35: 185-203.

Müller A, HT Vu, JG Ferraro, JE Keeffe and HR Taylor, 2006. Utilization of eye care services in Victoria. Clin. Experiment. Ophthalmol., 34: 445-448.

Ono K, Y Hiratsuka and A Murakami, 2010. Global inequality in eye health: country-level analysis from the global burden of disease study. Am. J. Public Health, 100: 1784-1788.

Rahmathullah L, BA Underwood, RD Thulasiraj, RC Milton, K Ramaswamy, R Rahmathullah and G Babu, 1990. Reduced Mortality among Children in Southern India Receiving a Small Weekly Dose of Vitamin A. N. Engl. J. Med., 323: 929-935.

Shrestha MK, CW Guo, N Maharjan, R Gurung and S Ruit, 2014. Health common ocular diseases in Nepal. BMC Ophthalmol., 14: 2.

Solomon SD, E Chew, EJ Duh, L Sobrin, JK Sun, BL VanderBeek, CC Wykoff and TW Gardner, 2017. Diabetic Retinopathy: A Position Statement by the American Diabetes Association. Diabetes Care, 40: 412418.

Varma R, PP Lee, I Goldberg and S Kotak, 2011. An assessment of the health and economic burdens of glaucoma. Am. J. Ophthalmol., 152: 515-522.

Yu X, D Lyu, X Dong, J He and K Yao, 2014. Hypertension and Risk of Cataract: A Meta-Analysis. PLoS ONE, 9: e114012. 